\title{
Effect of electric pulse charged to culture soil on improvement of nutritional soil condition and growth of lettuce (Lactuca sative L.)
}

\author{
Jun Young $\mathrm{Yi}^{1}$, Ji Won Choi ${ }^{1}$, Bo Young Jeon ${ }^{1}$, Il Lae Jung ${ }^{2}$, Doo Hyun Park ${ }^{1^{*}}$ \\ ${ }^{1}$ Department of Biological Engineering, Seokyeong University, Seoul, South Korea; ${ }^{*}$ Corresponding Author: baakdoo@skuniv.ac.kr \\ ${ }^{2}$ Department of Radiation Biology, Environmental Radiation Research Group, Korea Atomic Energy Research Institute, Daejeon, \\ South Korea
}

Received 29 August 2012; revised 30 September 2012; accepted 10 October 2012

\begin{abstract}
This study is intended to measure variations of nutritional soil condition and mass spectrometric patterns to describe the specific effects of electric pulse charged to culture soil which induced an increase of lettuce growth. In a previous study, lettuce cultivated in an electrically pulsed culture soil (EPCS) grew more actively than those in a conventional culture soil (CCS). Lettuce growth increased about $20 \%$ more in EPCS than CCS during cultivated for 21 days in this study. Content of nutrient salts and minerals varied in CCS and EPCS when assayed after the period of lettuce cultivation. Ammonium content in CCS was higher than that in EPCS but nitrate content was opposite of the ammonium. Inorganic N-compounds in EPCS was about 2.5 times higher than that in CCS. Content of phosphate in CCS increased greatly by lettuce cultivation but was about 2 times lower than that in EPCS. Contents of minerals in EPCS were relatively higher than those in CCS excepting Fe. Patterns of chromatography and mass spectrometry for water soluble compounds extracted from lettuces cultivated in EPCS were considerably different from those in CCS. Conclusively, electric pulse caused increased lettuce growth, improved nutritional soil conditions, and varied mass spectrometric patterns.
\end{abstract}

Keywords: Electrically Pulsed Soil; Lettuce; Inorganic Nutrients; Minerals; Weathering

\section{INTRODUCTION}

In previous research, we found a new phenomenon, that lettuce growth was significantly increased while rooting from branch cuttings of hot pepper plant was activated by the electric pulse charged to the culture soil [1]. Theoretically, electric pulse energy charged to soil influences physiological function of some soil bacteria and induces a geochemical change of soil conditions for plants and bacterial communities. The diversity of soil bacterial community was not changed by the electric pulse, contrary to expectation [1-3]. Accordingly, the effect of electric pulse on activation of lettuce growth may be unrelated to soil bacterial communities since bacterial communities inhabiting soil and rhizosphere improve nutritional conditions for plants [4-7].

Exudates extracted from plant's roots are nutrients for soil bacteria, growing cells of bacteria, and activate biological weathering of soil particles. Electrochemical redox reaction generated by electric pulse charged to plant culture soil may activate physicochemical weathering to produce water-soluble minerals from soil particles $[8,9]$. Both water-soluble and water-insoluble ions may be influenced by the electrochemical redox reaction with accompanying migration of positive and negative electric charges [10]. Some of adsorbed organic and inorganic compounds onto soil particles may be desorbed in the pulsed electric field generated between anode and cathode [11-13]. While the electric pulse generated from 10 $\mathrm{V}$ of electricity may be not enough to induce physiological function of soil bacteria to be activated or repressed, it may be enough to induce improvement of nutritional soil condition in EPCS by the physicochemical weathering.

A high intensity electric pulse generated from more than $1 \mathrm{kV} \cdot \mathrm{cm}^{-1}$ of electric intensity has been known to irreversibly change cytoplasmic membrane of microorganisms $[14,15]$ and completely inactivate both gram $(+)$ and gram $(-)$ bacteria [16,17]. High intensity electric pulses are useful for preservation of foods, sterilization of treated wastewater effluent, and sterilization of medical apparatus. These pulses, however, are of limited ef- 
fect and use for destruction of microorganism [18]. The low intensity electric pulse generated from $1.0 \mathrm{~V} \cdot \mathrm{cm}^{-1}$ of electricity didn't inhibit bacterial growth or destroy bacterial structure based on the TGGE patterns of bacterial communities grown in electric pulse but improved the environmental condition of the soil for lettuce growth [1].

The goal of this study is to explore why lettuce growth was increased by the electric pulse charged to culture soil without accompanying change in the bacterial community. To this end the changes in inorganic nutrients and minerals in the two test soils prepared for lettuce growth were quantitatively compared, and organic compounds extracted from lettuces cultivated in those soils were qualitatively compared with liquid chromatography and mass spectrometry.

\section{MATERIALS AND METHODS}

\subsection{Lab-Scale Farm Field}

The lab-scale farm field and culture soil used in the previous study was employed in this study without modification [1]. Ten $\mathrm{V}$ of electric pulse was charged to the lettuce culture soil (EPCS) but not to the control soil (CCS).

\subsection{Cultivation of Lettuces}

Fifteen lettuces that were previously germinated and then cultivated in a green house under sunlight for 10 days were transplanted into CCS and EPCS of the prepared lab-scale farm field. The lettuces were cultivated for 21 days. Two $\mathrm{L}$ of water was sprayed on the soil in each culture soil at 3 - 4 day intervals. A plant growthpromoting lamp was used for lighting and adjusted to an illumination intensity of 20,000 lux measured at the surface of the compost soil. Air temperature around the lab-scale farm field was maintained at $18^{\circ} \mathrm{C}-25^{\circ} \mathrm{C}$ and the dark-light interval was set to $12 \mathrm{hr}$.

\subsection{Preparation of Samples for Analysis}

Lettuces were cut at interface between stem and root and immediately weighed using a precision balance. All lettuces were lyophilized after weighing to prevent biochemical or chemical reactions from occurring. The completely dried lettuces were ground to fine powder. The lettuce powder was quantitatively extracted with double distilled water just before analyzed. After lettuces were harvested, culture soils were uniformly sampled at 20 points in CCS and EPCS and immediately lyophilized to prevent biochemical reactions possibly generated by bacterial growth. The lyophilized soils were quantitatively extracted with double distilled water just before analyzed. Fresh soil was not lyophilized because it was originally dried.

\subsection{Analysis of Inorganic Nutrients}

Nitrate, nitrite, and phosphate were analyzed using an ion chromatograph (Dionex DX-500, USA) equipped with an anion column (IonPac, Dionex AS14A). Mixture of $8.0 \mathrm{mM}$ sodium carbonate and $2.0 \mathrm{mM}$ sodium bicarbonate was used as a mobile phase. Flow rates and column temperature were adjusted to $0.5 \mathrm{ml} / \mathrm{min}$ and $30^{\circ} \mathrm{C}$, respectively. Ammonium was analyzed using an ion chromatograph (Dionex DX-500, USA) equipped with a cation column (IonPac, Dionex CS12A). 100\% $20 \mathrm{mM}$ methanesulfonic acid was used as a mobile phase. Column temperature and flow rate were adjusted to $35^{\circ} \mathrm{C}$ and $0.8 \mathrm{ml} / \mathrm{min}$.

\subsection{Analysis of Minerals}

Mineral content was analyzed using inductively coupled plasma (ICP) optic emission spectrometry (SPECTRO Analytical Instruments, Kleve, Germany). The extract prepared for mineral analysis was directly injected into the ICP injector under specific wavelengths for $\mathrm{Mg}$ $(279.079 \mathrm{~nm}), \mathrm{Na}(589.592 \mathrm{~nm}), \mathrm{K}(766.491 \mathrm{~nm}), \mathrm{Ca}$ $(396.847 \mathrm{~nm}), \mathrm{Mn}(257.610 \mathrm{~nm}), \mathrm{Zn}(213.856 \mathrm{~nm}), \mathrm{Al}$ $(167.080 \mathrm{~nm}), \mathrm{Cu}(324.745 \mathrm{~nm})$, and $\mathrm{Fe}(238.204 \mathrm{~nm})$. The mineral concentrations were calculated based on the absorbance obtained with standard materials (AccuTrace Reference Standard; AccuStandard, New Haven, CT, USA) and dilution ratio.

\subsection{Liquid Chromatography and Mass Spectrometry}

A combined system of mass spectrometry (ThermoFinnegan LTQ-Orbitrap instrument, Thermo Scientific, USA) and HPLC system (Dionex U3000, USA) was used for analysis of organic compounds extracted from the lettuces cultivated in CCS and EPCS. HPLC system was composed of a photodiode array detector (Dionex PDA 3000), an auto sampler (Dionex WPS3000SL), and a reversed phase column (U10, Imtakt Unison UK-C18, Scientific Instrument Services, USA). The injection volume was $10 \mathrm{~mL}$ and the flow rate $200 \mathrm{~mL} / \mathrm{min}$. Gradient elution of mobile phase consisted of $15 \%$ formic acid (A) and acetonitrile (B) was adjusted by timecoursed percentage balance between $\mathrm{A}$ and $\mathrm{B}$ as follows: $95 \% \mathrm{~A}$ and $5 \% \mathrm{~B}$ at initial time, $70 \% \mathrm{~A}$ and $30 \% \mathrm{~B}$ from initial to $20 \mathrm{~min}, 20 \% \mathrm{~A}$ and $80 \% \mathrm{~B}$ from 20 to $24 \mathrm{~min}$, and $95 \% \mathrm{~A}$ and $5 \% \mathrm{~B}$ from 24 to $30 \mathrm{~min}$. Mass spectrometric analysis were performed using a Thermo-Finnegan LTQ-Orbitrap ion trap mass spectrometer with electrospray ionization (ESI) interface. The capillary temperature was maintained at $275^{\circ} \mathrm{C}$; the ion source voltage 
was set at $5000 \mathrm{~V}$ and the nebulizer gas was set at 300 units. The capillary voltage was set at $8 \mathrm{~V}$ to be analyzed in negative ionization mode. The collision energy was generally chosen in order to maintain about $35 \%$ abundance of the precursor ion.

\section{RESULTS}

\subsection{Variation of Lettuce Growth}

Lettuces were cultivated in CCS and EPCS under control of temperature and lighting intensity for 21 days, a relatively short period of time intended to compare electric pulse effect on lettuce growth without interference from effects such as natural withering of leaves, shading of light by upper leaves, exhaustion of soil nutrients, and environmental variation. The mean weight of lettuces cultivated in CCS and EPCS was about 20.5 and $24.5 \mathrm{~g}$, respectively, as shown in Table 1. Lettuce growth in EPCS was $20 \%$ higher than those in CCS based on the weight of the edible part of fresh lettuce without roots. A difference of $20 \%$ is enough to evaluate effect of the electric pulse.

\subsection{Variation of Nutrient Salts in Culture Soil}

Content of ammonium, nitrate, nitrite, and total nitrogen in fresh soil was $0.64,12,0.15$, and $12.8 \mathrm{mg} / \mathrm{Kg}$, which was increased or decreased in CCS and EPCS for 21 days as shown in Table 2. Nutrient salts may be generally decreased in proportion to the content consumed by growing lettuces based on the total nitrogen contents; however, ammonium and nitrite were increased in CCS but decreased in EPCS. This may result from biochemical or chemical reactions of nitrogen ions catalyzed by bacterial metabolism or induced by electrochemical redox reaction. Phosphate content was greatly increased by lettuce cultivation and more than double in EPCS than in CCS. This may be caused by bacteriological and electrochemical weathering.

\subsection{Variation of Minerals Content in Culture Soil}

Minerals content in soil can exist as free ions or adsorbed ion in proportion to the solubility in water. Accordingly, the content of water-soluble minerals may decrease in proportion to the lettuce growth. As shown in Table 3, content of minerals extracted from lyophilized soils by water were generally decreased in both CCS and EPCS except Fe. However, contents of most minerals was a little or significantly higher in EPCS than those in CCS. This phenomenon may be caused by an increase of water soluble ions. Metal ions can be chemically separated from vermiculite, zeolite and perlite by weathering,
Table 1. Weight of lettuces cultivated in conventional culture soil (CCS) and $10 \mathrm{~V}$ of the electrically pulsed culture soil (EPCS) for 21 days after young lettuce saplings were transplanted.

\begin{tabular}{ccc}
\hline Crop No. & CCS & EPCS \\
\hline 1 & 32.46 & 32.52 \\
2 & 27.62 & 32.33 \\
3 & 25.37 & 30.16 \\
4 & 24.45 & 28.40 \\
5 & 23.78 & 28.35 \\
6 & 23.64 & 27.95 \\
7 & 23.52 & 27.39 \\
8 & 19.72 & 27.33 \\
9 & 19.41 & 26.11 \\
10 & 18.53 & 22.31 \\
11 & 17.24 & 22.27 \\
12 & 15.85 & 20.71 \\
13 & 15.73 & 15.85 \\
14 & 13.44 & 15.24 \\
15 & 6.67 & 10.96 \\
Mean \pm STD & $20.49 \pm 6.14$ & $24.52 \pm 5.18$ \\
\hline
\end{tabular}

Table 2. Contents of water-soluble nutrient salts in conventional culture soil (CCS) and $10 \mathrm{~V}$ of the electrically pulsed culture soil (EPCS) measured at 21st day after young lettuce saplings were transplanted.

\begin{tabular}{cccc}
\hline Salts $(\mathrm{mg} / \mathrm{Kg})$ & Fresh soil & $\mathrm{CCS}$ & EPCS \\
\hline $\mathrm{NH}_{4}^{+}-\mathrm{N}$ & $0.64 \pm 0.01$ & $1.08 \pm 0.03$ & $0.51 \pm 0.02$ \\
$\mathrm{NO}_{3}^{-}-\mathrm{N}$ & $12.0 \pm 0.3$ & $2.4 \pm 0.1$ & $8.3 \pm 0.2$ \\
$\mathrm{NO}_{2}^{-}-\mathrm{N}$ & $0.15 \pm 0.001$ & $0.18 \pm 0.001$ & $0.03 \pm 0.001$ \\
$\begin{array}{c}\text { Total nitrogen } \\
\text { contents }\end{array}$ & $12.79 \pm 0.31$ & $3.66 \pm 0.13$ & $8.84+0.22$ \\
$\mathrm{PO}_{4}^{3-}$ & $4.6 \pm 0.7$ & $32.5 \pm 1.2$ & $70.3 \pm 1.6$ \\
\hline
\end{tabular}

Table 3. Contents of minerals in conventional culture soil (CCS) and $10 \mathrm{~V}$ of the electrically pulsed culture soil (EPCS) measured at 21 st day after young lettuce saplings were transplanted.

\begin{tabular}{cccc}
\hline $\begin{array}{c}\text { Minerals } \\
(\mathrm{mg} / \mathrm{Kg})\end{array}$ & Fresh soil & CCS & EPCS \\
\hline $\mathrm{K}$ & $80.20 \pm 2.2$ & $50.64 \pm 1.7$ & $55.39 \pm 1.8$ \\
$\mathrm{Mg}$ & $51.90 \pm 1.5$ & $19.05 \pm 0.8$ & $44.73 \pm 1.4$ \\
$\mathrm{Ca}$ & $54.03 \pm 1.5$ & $22.74 \pm 1.1$ & $46.13 \pm 1.5$ \\
$\mathrm{Mn}$ & $0.33 \pm 0.01$ & $0.03 \pm 0$ & $0.13 \pm 0.01$ \\
$\mathrm{Fe}$ & $0.53 \pm 0.01$ & $0.57 \pm 0.01$ & $0.54 \pm 0.01$ \\
$\mathrm{Zn}$ & $0.09 \pm 0.01$ & $0.03 \pm 0.01$ & $0.15 \pm 0.01$ \\
\hline
\end{tabular}


which may be activated by electrochemical redox reaction in pulsed electric field.

\subsection{HPLC and Spectrometry Patterns of Lettuce Extract}

Water extract of lettuces can contain a great variety of water-soluble metabolites and hormones produced and synthesized by growing lettuces. The concentration of lettuce extract was precisely adjusted in order to compare chromatographic pattern for extract of lettuces cultivated in CCS and EPCS. As shown in Figure 1, a chromatogram obtained in HPLC for compounds extracted from lettuces cultivated in EPCS (EPCS-extract) was significantly different from that in CCS (CCS-extract). The compounds detected at 1.74 min of retention time (RT 1.74), RT 6.70, RT 8.78, RT 10.87, RT 12.06, RT 12.99, RT 15.35, RT 22.92, and RT 23.25 in the chromatographic analysis for EPCS-extract were considerably higher than those in the chromatographic analysis for CCS-extract, caused perhaps by the difference in metabolic activity between lettuces cultivated in CCS and EPCS. The differences of chromatographic patterns and peak heights in HPLC for CCS- and EPCS-extract may be a clue that the lettuce growth is intimately related with metabolic activity. The compounds detected in box I, II, and III indicated in chromatograms were analyzed by mass spectrometry to estimate character of compounds fractionated by HPLC based on the released database of plant hormones $[19,20]$.

\subsection{Mass Spectrometric Patterns of Lettuce Extract}

Compounds fractionated at retention time within range from 0.95 to $2.37 \mathrm{~min}, 8.77$ to 15.97 , and 20.87 to 23.61 (box I, II, and III in Figure 1) were fragmented by electrospray ionization in mass spectrometry as shown in Figures 2-4, respectively. Precursor ion and product ions generated by electrospray ionization and collision can't be concretely characterized based on the molecular weight because a single specific compound detected in HPLC was not separately analyzed by mass spectrometry, and plant metabolites have not been listed in the database. However, plant hormones can be estimated based on the mass-to-charge ratio $(\mathrm{m} / \mathrm{z})$ of precursor ion and productions fragmented in mass spectrometry. The $\mathrm{m} / \mathrm{z}$ of precursor ion and product ions of standard materials of abscisic acid, indole-3-acetic acid, cytokinin, and gibberellin A4 fragmented by electrospray ionization in the mass spectrometry performed in the negative ionization mode (Table 4) was not identified with the $\mathrm{m} / \mathrm{z}$ of precursor ion or product ions fragmented by the mass spectrometry of lettuce extract performed in the negative ionization mode (Figures 2-4). These results may mean that the content of hormones in the lettuce extract are lower than

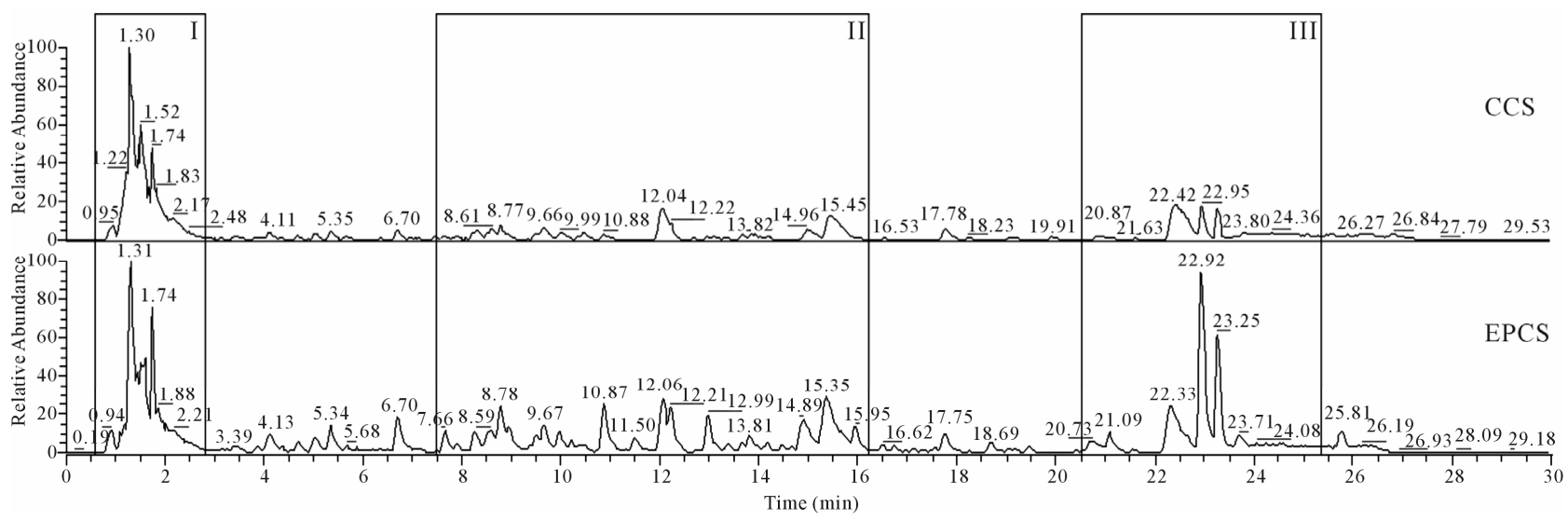

Figure 1. HPLC pattern of water-extracted compounds from lettuces that were grown in conventional culture soil (CCS) and electrically pulsed culture soil (EPCS) for 21 days and then harvested and lyophilized immediately.

Table 4. Molecular weight (MW) of precursor ion ionized generated by electrospray ionization and product ions generated by electrospray collision and ionization in mass spectrometry of representative plants' hormones [References].

\begin{tabular}{ccccccccc}
\hline \multirow{2}{*}{ Plant hormones } & precursor ion $(\mathrm{m} / \mathrm{z})$ & \multicolumn{7}{c}{ Product ions $(\mathrm{m} / \mathrm{z})$} \\
\cline { 3 - 8 } & & I & II & III & IV & V & VI & VII \\
\hline Abscisic acid & 263 & 111 & 153 & 163 & 204 & 219 & \\
Indole-3-acetic acid & 174 & 128 & 130 & & & & & \\
Cytokinin & 220 & 136 & 148 & 185 & 202 & & 287 & 313 \\
Gibberellin A4 & 331 & 213 & 225 & 240 & 257 & 269 & 287 \\
\hline
\end{tabular}



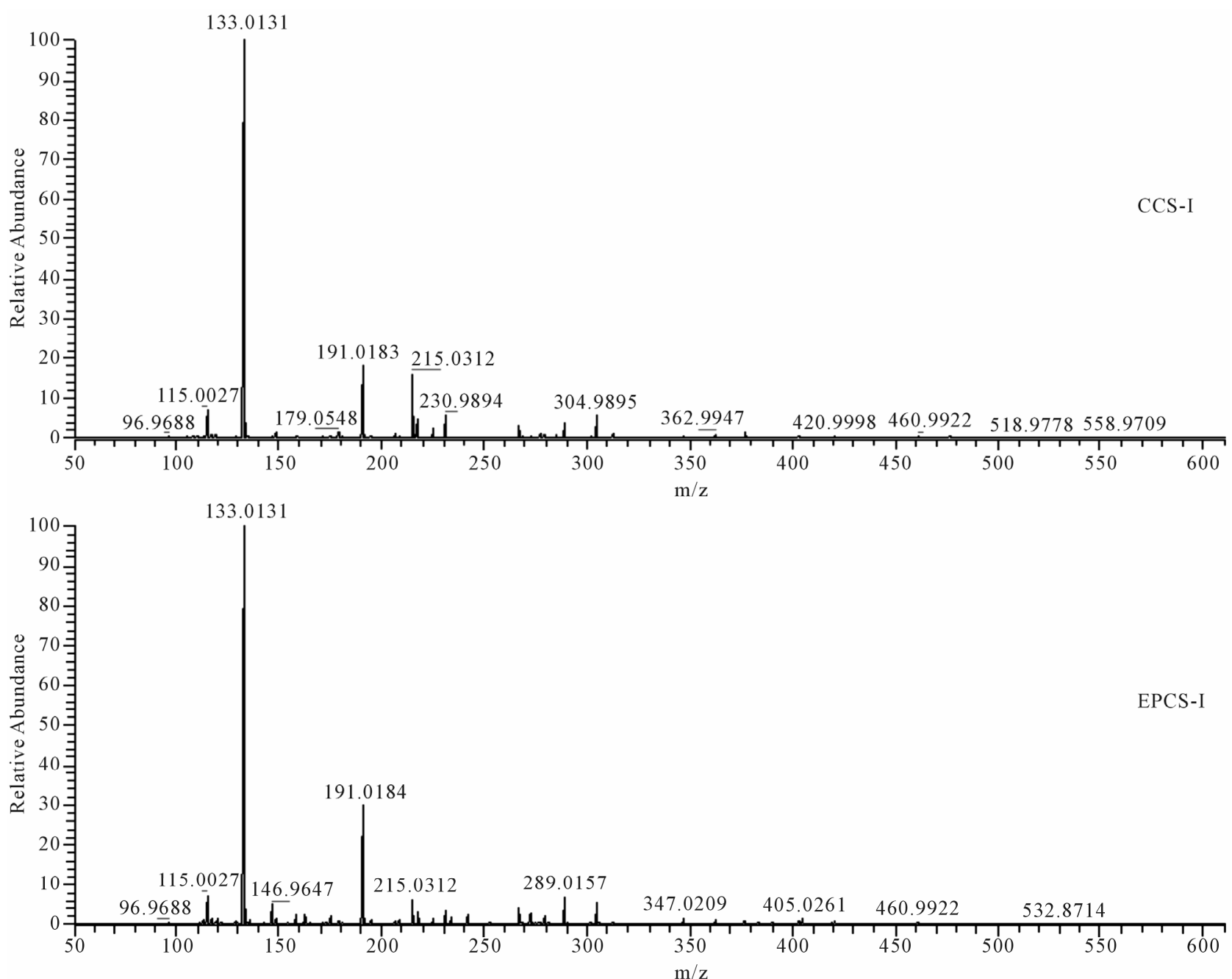

Figure 2. Fragmentation patterns for water-extracted compounds of lettuce detected at retention time from 0.95 to 2.37 min (Figure 1, box I) in HPLC.

detectable limits because the extract was 100 times diluted for control of HPLC peak area, or the concentration of hormones produced by lettuce may be relatively lower than other metabolites to be separately detected by HPLC. The $\mathrm{m} / \mathrm{z} 191$ (Figure 2), $\mathrm{m} / \mathrm{z} 179,225,277,311$, 339, 431, 471, 540, and 702 (Figure 3), and m/z 327, 481, and 655 (Figure 4) in fragmentation patterns for water extract of lettuces cultivated in EPCS was significantly different from those in CCS, indicating that production of specific metabolites may change with variation of soil conditions induced by electric pulse or directly influenced by the electric pulse.

\section{DISCUSSION}

Biogeochemical condition of culture soil for growth of each lettuce may not be very different but may be changed by electric pulse based on the weight difference of lettuces cultivated in CCS and EPCS. Twenty percent increase of crop weight in EPCS may be caused by improvement of nutritional soil condition for lettuce growth or physiological activation of lettuces by the electric pulse. Ammonium and nitrate are commonly absorbable nutrient ions by plants but nitrite is not $[21,22]$. However, nitrite can be chemically and biochemically oxidized to nitrate and biochemically reduced to ammonium [23-25]. Electrochemical redox reactions induced by the electric pulse may activate oxidation of nitrite to nitrate [26]. Total nitrogen contents may thus be useful to estimate nutritional soil condition for lettuce growth. The total nitrogen content in EPCS was more than double that in CCS, reciprocally proportional to weight of lettuces. Inorganic nitrogen may be more effectively generated from soils composed of organic and inorganic nitrogen compounds by biochemical and chemical reaction in EPCS than CCS. Phosphate has a strong tendency to be adsorbed onto soil particles and readily becomes a waterinsoluble salt. However, phosphate may be desorbed by 

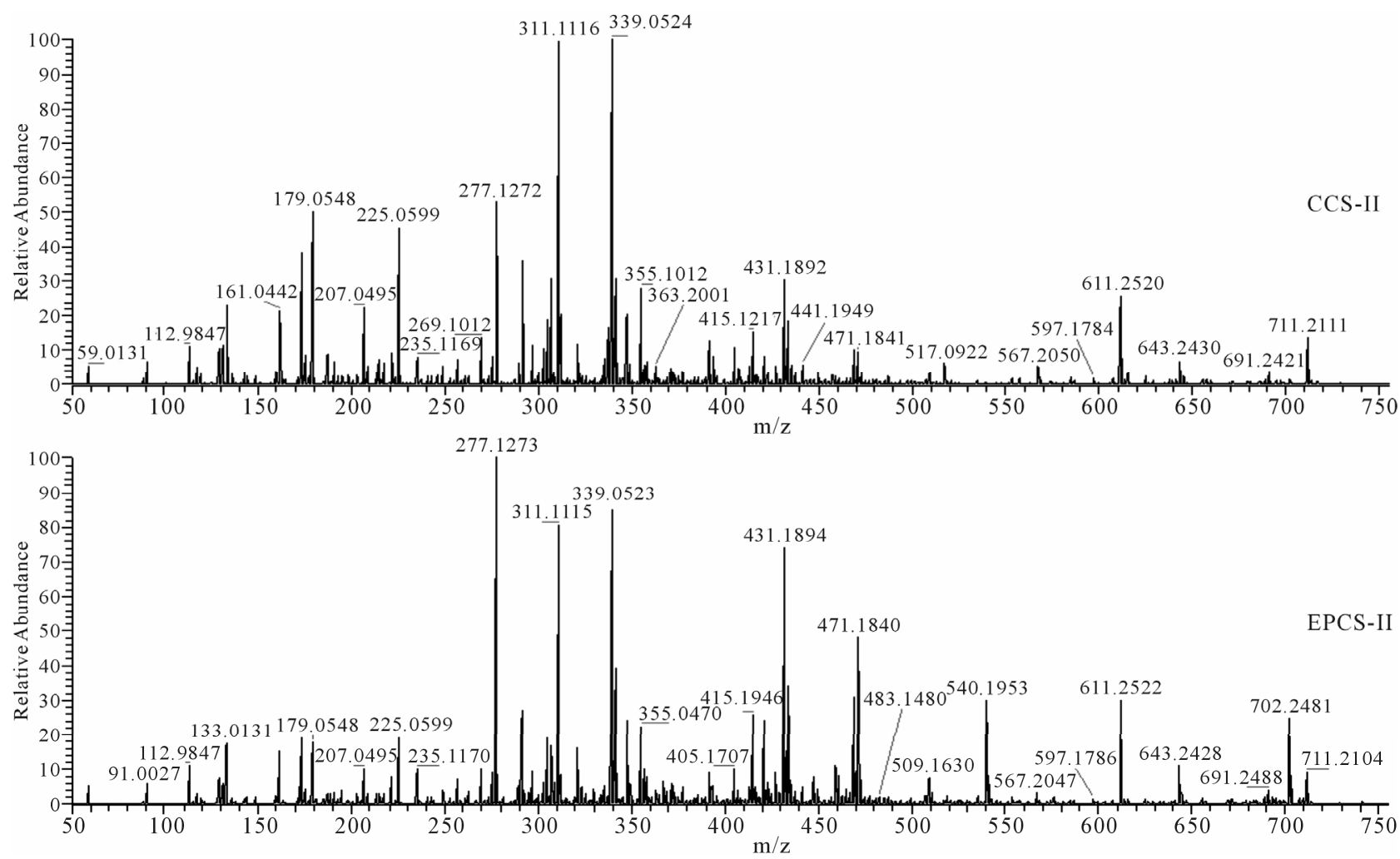

Figure 3. Fragmentation patterns for water-extracted compounds of lettuce detected at retention time from 8.77 to 15.97 min (Figure 1, box II) in HPLC.
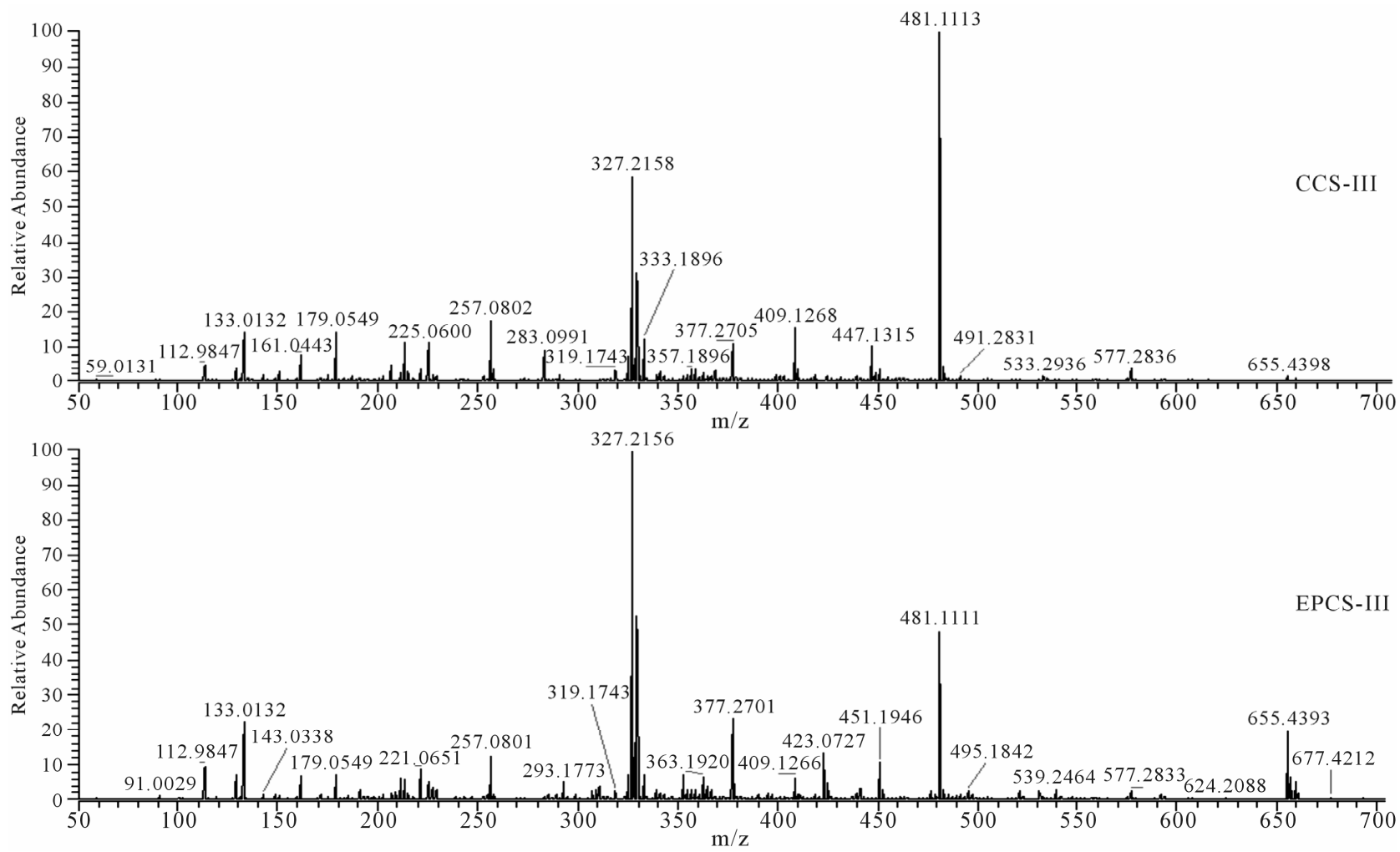

Figure 4. Fragmentation patterns for water-extracted compounds of lettuce detected at retention time from 20.87 to $23.61 \mathrm{~min}$ (Figure 1, box III) in HPLC. 
biological weathering induced by bacterial metabolites and exudate secreted by roots of plants [27-29]. Higher phosphate in EPCS than CCS may be caused by additional weathering induced by the electric pulse [30]. Minerals also may be dissolved in watered soil by the biochemical weathering induced by microbial metabolism, roots of plants [31] and chemical weathering induced by electric pulse [32]. Nutrient salts and minerals are essential factors for plant growth, which may be more effectively balanced or increased for lettuce growth in EPCS than CCS [33].

Nutritional soil conditions were improved by the electric pulse. However, the improvement of nutritional soil condition may not have increased lettuce growth based on the difference of HPLC and mass spectrometry pattern for water extract of lettuces cultivated in CCS and EPCS. Difference of peak patterns in HPLC and fragmentation patterns in mass spectrometry for lettuces cultivated in CCS and EPCS are an indicator that some organic compounds produced by lettuces are directly influenced by the electric pulse or indirectly by variation of nutritional soil condition induced by the electric pulse. Metabolites produced by growing lettuces may be sugars, organic acids, amino acids, nucleic acids, and fatty acids. Practically, most of the metabolites produced in cells of lettuces grown for 21 days may be converted to structural polymers. Metabolite concentrations may be difficult to measure without separate purification. However, the differences of metabolites of hormones produced by lettuces grown in CCS and EPCS can be compared using patterns of HPLC and mass spectrometry. Hormones produced by lettuces can be identified using the fragmentation $(\mathrm{m} / \mathrm{z})$ pattern of precursor ions and product ions generated by electrospray ionization of standard hormones. The $\mathrm{m} / \mathrm{z}$ patterns of organic compounds contained in lettuce extract were compared with the mass spectrometric database obtained using the standard hormones $[19,20]$. The $\mathrm{m} / \mathrm{z}$ patterns obtained in mass spectrometry for the lettuce extract were not identified with the $\mathrm{m} / \mathrm{z}$ pattern for the standard hormone (Table 4 and Figures 2-4). Variation and difference of $\mathrm{m} / \mathrm{z}$ pattern in the mass spectrometry for lettuce extract can be an indicator to clearly show difference of metabolites produced by lettuces grown in CCS and EPCS. The difference of peak height and $\mathrm{m} / \mathrm{z}$ pattern in the mass spectrometry for the lettuce extract does not predict whether the electric pulse charged to lettuce culture soil directly or indirectly activates lettuce growth by improvement of nutritional soil condition. Conclusively, the low intensity electric pulse charged to the culture soil for lettuce cultivation influenced improvement of nutritional soil condition for the water-soluble nutrient salts and minerals and increase of some organic compounds contained in lettuce extract. The relatively higher content of water-soluble organic compounds, of which molecular weight is possible to be minimally 133 (Figure 2) and maximally 711 (Figure 3) based on the $\mathrm{m} / \mathrm{z}$ measured by the mass spectrometry, may be a clue that building blocks for biosynthesis of structural compounds may be more actively produced.

\section{AKNOWLEDGEMENTS}

This work was supported by the New \& Renewable Energy of the Korea Institute of Energy Technology Evaluation and Planning (KETEP) grant funded by the Korea governmental Ministry of Knowledge Economy (2010T1001100334).

\section{REFERENCES}

[1] Yi, J.Y., Choi, J.W., Jeon, B.Y. and Park, D.H. (2012) Effect of a low-voltage electric pulse charged to culture soil on plant growth and variation of the bacterial community. Agricultural Sciences, 3, 339-346. doi:10.4236/as.2012.33038

[2] Liu, S.Q., Wu, N.J. and Ignatiev, A. (2000) Electricpulse-induced reversible resistance change effect in magnetoresitive films. Applied Physics Letters, 76, 27492751. doi:10.1063/1.126464

[3] Meilhoc, E., Masson, J.M. and Teissié, J. (1990) High efficiency transformation of intact yeast cells by electric field pulse. Nature Biotechnology, 8, 223-227. doi:10.1038/nbt0390-223

[4] Glick, B.R., Karaturovic, D.M. and Newell, P.C. (1995) A novel procedure for rapid isolation of plant growth promoting Pseudomonads. Canadian Journal of Microbiology, 41, 533-536. doi:10.1139/m95-070

[5] Kennedy, I.R., Perg-Gerk, L.L., Wood, C., Deaker, R., Gilchrist, K. and Katupitiya, S. (1997). Biological nitrogen fixation in non-leguminous field crop: Facilitating the evolution of an effective association between Azospirillum and wheat. Plant Soil, 194, 65-79. doi:10.1023/A:1004260222528

[6] Kleeberger, A., Castroph, H. and Klingmuller, W. (1983) The rhizosphere microflora of wheat and barley with special reference to gram-negative bacteria. Archives of $\mathrm{Mi}$ crobiology, 136, 306-311. doi:10.1007/BF00425222

[7] Sakthivel, N. and Gnanamanikam, SS. (1987) Evaluation of Pseudomonas fluorescens for suppression of sheath rot disease and for enhances in rice (Oryza sativa L.). Applied and Environmental Microbiology, 53, 2056-2059.

[8] Ochs, M., Brunner, I., Stumm, W. and Ćosović, B. (1993) Effects of root exudates and humic substances on weathering kinetics. Water, Air and Soil Pollution, 68, 213-229. doi:10.1007/BF00479404

[9] House, K.Z., House, C.H., Schrag, D.P. and Aziz, M.J. (2007) Electrochemical accelaeation of chemical weathering as an energetically feasible approach to mitigating anthropogenic climate change. Environmental Science \& Technology, 41, 8864-8870. doi:10.1021/es0701816

[10] Jenny, H. and Overstreet, R. (1939) Surface migration of ions and contact exchange. Journal of Physical Chemistry, 


\section{3, 1185-1196. doi:10.1021/j150396a010}

[11] Unwin, P.R. and Bard, A.J. (1992) Scanning electrochemical microscopy. 14. Scanning electrochemical microscope induced desorption: A new technique for the measurement of adsorption/desorption kinetics and surface diffusion rates at the solid/liquid interface. The Journal of Physics Chemistry, 96, 5035-5045.

[12] Zhou, W., Inoue, S., Iwahashi, t., Kanai, K., Seki, K., Miyamae, T., Kim D., Katayama, Y. and Ouchi, Y. (2010) Double layer structure and adsorption/desorption hysteresis of neat inonic on Pt electrode surface-an in-situ IRvisible sum-frequency generation spectroscopic study. Elec-trochemistry Communication, 12, 672-675. doi:10.1016/j.elecom.2010.03.003

[13] Yeung, A.T. Hsu, C. and Menon, R.M. (1997) Physicochemical soil-contaminant interactions during electrokinetic extraction. Journal of Hazardous Materials, 55, 221-237. doi:10.1016/S0304-3894(97)00017-4

[14] Palaniappan, S., Sastry, S.K. and Richter, E.R. (1990) Effects of electricity on microorganisms: A review. Journal of Food Processing \& Preservation, 14, 393-414. doi:10.1111/j.1745-4549.1990.tb00142.x

[15] Zhang, Q., Qin, B.L., Barbosa-Cánovas, G.V. and Swanson, B.G. (1995) Inactivation of E. coli for food pasteurization by high-strength pulsed electric fields. Journal of Food Processing \& Preservation, 19, 103-118. doi:10.1111/j.1745-4549.1995.tb00281.x

[16] Grahl, T. and Maerkl, H. (1996) Killing of microorganisms by pulsed electric fields. Applied Microbiology and Biotechnology, 45, 148-157. doi:10.1007/s002530050663

[17] Hulsheger, H., Potel, J. and Niemann, E.G. (1983) Electric field effects on bacteria and yeast cells. Radiation and Environmental Biophysics, 22, 149-162. doi:10.1007/BF01338893

[18] Marquez, V.O., mittal, G.S. and Griffiths, M.W. (1997) Destruction and inhibition of bacterial spores by high voltage pulsed electric field. Food Science, 62, 399-401. doi:10.1111/j.1365-2621.1997.tb04010.x

[19] Chiwacha, S.D.S., Abrams, S.R., Amberose, S.J., Cutler, A.J., Loewen, M., Ross, A.R.S. and Kermode, A.R. (2003) A method for profiling classes of plant hormones and their metabolites using liquid chromatography-electrospray ionization tandem mass spectrometry: An analysis of hormone regulation of thermodormancy of lettuce (Lactuca sativa L.) seeds. The Plant Journal, 35, 405471. doi:10.1046/j.1365-313X.2003.01800.X

[20] Kojima, M., Kamada-Nobusada, T., Komatsu, H., Takei, K., Kuroha, T., Mizutani, M., Ashikari, M., Ueguchi-Tanaka, M., Matsuoke, M., Suzuki, K. and Sakakibara, H. (2009) Highly sensitive and high-throughput analysis of plant hormones using ms-probe modification and liquid chromatography-tandem mass spectrometry: An application for hormone profiling in Oryza sativa. Plant Cell Physiology, 50, 1201-1214. doi:10.1093/pcp/pcp057
[21] Kronzucker, H.J., Siddiqi, M.Y., Glass A.D.J. and Kirk G.J.D. (1999) Nitrate-ammonium synergism in rice. A subcellular flux analysis. Plant Physiology, 119, 10411046. doi:10.1104/pp.119.3.1041

[22] Cao, W. and Tibbits, T.W. (1993) Study of various $\mathrm{NH}_{4}^{+} / \mathrm{NO}_{3}^{-}$mixtures for enhanced growth of potatoes. Journal of Plant Nutrition, 16, 1691-1704. doi:10.1080/01904169309364643

[23] Lees, H. and Simpson, J.R. (1957) The biochemistry of the nitrifying organisms. Nitrite oxidation by Nitrobacter. Biochemical Journal, 65, 297-305.

[24] Belser, L.W. and Mays, E.L. (1980) Specific inhibition of nitrite oxidation by chlorate and its use in assessing nitrification in soil and sediments. Applied and Environmental Microbiology, 39, 505-510.

[25] Rice, C.W. and Tiedje, J.M. (1989) Regulation of nitrate assimilation by ammonium in soils and in isolated soil microorganisms, Soil Biology and Biochemistry, 21, $597-$ 602. doi:10.1016/0038-0717(89)90135-1

[26] Jiang, L., Wang R., Li, X., Jiang, L. and Lu, G. (2005) Electrochemical oxidation behavior of nitrite on a chitosan-carboxylated multiwall carbon modified electrode. Electrochemistry Communication, 7, 597-601. doi:10.1016/j.elecom.2005.04.009

[27] Freitas, J.R., Banerjee, M.R. and Germida, J.J. (1997) Phosphate-solubilizing rhizobacteria enhance the growth and yield but not phosphorus uptake of canola (Brassica napus L.). Biology and Fertility of Soil, 24, 358-364. doi:10.1007/s003740050258

[28] Narsian, V. and Patel, H.H. (2000) Aspertgillus aculeatus as a rock phosphate solubilizer. Soil Biology\& Biochemistry, 32, 559-565. doi:10.1016/S0038-0717(99)00184-4

[29] Hilda, R. and Reynaldo, F. (1999) Phosphate solubilizing bacteria and their role in plant growth promotion. Biotechnology Advances, 17, 319-339. doi:10.1016/S0734-9750(99)00014-2

[30] Shenker, M., Seitelbach, S., Brand, S., Haim, A. and Litaor, M.I. (2005) Redox reactions and phosphorus release in re-flooded soils of an altered wetland. European Journal of Soil Science, 56, 515-525. doi:10.1111/j.1365-2389.2004.00692.x

[31] Uroz, S., Calvaruso, C., Turpault, M.P. and Frey-Klett, P. (2009) Mineral weathering by bacteria: Ecology, actors and mechanisms. Trends in Microbiology, 17, 378-387. doi:10.1016/j.tim.2009.05.004

[32] Ayllon, E.S., Granese, S.L. and Rosales, B.M. (1990) Electrochemical response of weathering and plain c steels in different environments. Corrosion Reviews, 9, 246269. doi:10.1515/CORRREV.1990.9.3-4.245

[33] Yamaguchi, K.E. (2001) Evolution of the geochemical cycles of redox-sensitive elements. Frontier Research on Earth Evolution, 1, 249-252. 